\title{
OCCUPATIONAL EXPOSURE TO ELECTROMAGNETIC FIELDS IN THE POLISH ARMED FORCES
}

\section{JAROMIR SOBIECH, JAROSŁAW KIELISZEK, ROBERT PUTA, DAGMARA BARTCZAK, and WANDA STANKIEWICZ}

Military Institute of Hygiene and Epidemiology, Warszawa, Poland

Department of Microwave Safety

\begin{abstract}
Objectives: Standard devices used by military personnel that may pose electromagnetic hazard include: radars, missile systems, radio navigation systems and radio transceivers. The aim of this study has been to evaluate the exposure of military personnel to electromagnetic fields. Material and Methods: Occupational exposure to electromagnetic fields was analyzed in the work environment of personnel of 204 devices divided into 5 groups (surface-to-air missile system radars, aircraft and helicopters, communication devices, surveillance and height finder radars, airport radars and radio navigation systems). Measurements were carried out at indicators, device terminals, radio panels, above vehicle seats, in vehicle hatches, by cabinets containing high power vacuum tubes and other transmitter components, by transmission lines, connectors, etc. Results: Portable radios emit the electric field strength between $20-80 \mathrm{~V} / \mathrm{m}$ close to a human head. The manpack radio operator's exposure is $60-120 \mathrm{~V} / \mathrm{m}$. Inside vehicles with high frequency/very high frequency (HF/VHF) band radios, the electric field strength is between $7-30 \mathrm{~V} / \mathrm{m}$ and inside the radar cabin it ranges between 9-20 V/m. Most of the personnel on ships are not exposed to the electromagnetic field from their own radar systems but rather by accidental exposure from the radar systems of other ships. Operators of surface-to-air missile systems are exposed to the electric field strength between $7-15 \mathrm{~V} / \mathrm{m}$ and the personnel of non-directional radio beacons $-100-150 \mathrm{~V} / \mathrm{m}$. Conclusions: In $57 \%$ of military devices Polish soldiers work in the occupational protection zones. In $35 \%$ of cases, soldiers work in intermediate and hazardous zones and in $22 \%$ - only in the intermediate zone. In $43 \%$ of devices, military personnel are not exposed to electromagnetic field. Int J Occup Med Environ Health 2017;30(4):565-577
\end{abstract}

Key words:

Electromagnetic field, Occupational exposure, Soldiers, Measurements, Radar, Radio

\section{INTRODUCTION}

\section{Requirements for the protection of soldiers} against exposure to electromagnetic fields

Safety requirements for the protection of the Polish military personnel against exposure to electric field in the frequency range from $0 \mathrm{~Hz}$ to $300 \mathrm{GHz}$ and to magnetic field in the frequency range from $0 \mathrm{~Hz}$ to $3 \mathrm{GHz}$ are set forth in regulations [1-5]. These regulations define levels of exposure (exposure to electric field strength: $\mathrm{E}_{0}, \mathrm{E}_{1}, \mathrm{E}_{2}$ and to magnetic field strength: $\mathrm{H}_{0}, \mathrm{H}_{1}, \mathrm{H}_{2}$ ) as well as areas of occupational exposure (intermediate, hazardous and dangerous zones). $\mathrm{E}_{0}$ and $\mathrm{H}_{0}$ are low levels of occupational exposure. $\mathrm{E}_{1}$ and $\mathrm{H}_{1}$ separate an intermediate and a hazardous zone. $\mathrm{E}_{2}$ and $\mathrm{H}_{2}$ separate a hazardous and a dangerous

The paper refers to Polish regulations before July 1, 2016. However, keeping in mind the current legal requirements for the protection of workers against electromagnetic fields, the results of the paper remain current.

Received: May 29, 2015. Accepted: July 1, 2016.

Corresponding author: J. Sobiech, Military Institute of Hygiene and Epidemiology, Department of Microwave Safety, Kozielska 4, 01-163 Warszawa, Poland (e-mail: jaromirsobiech@gmail.com). 
zone. In an intermediate zone soldiers may stay during an entire shift. In a hazardous zone they may stay temporarily, while a dangerous zone indicates areas that are accessed only with protective clothing. The values of occupational exposure levels $\mathrm{E}_{0}, \mathrm{E}_{1}, \mathrm{E}_{2}$ and $\mathrm{H}_{0}, \mathrm{H}_{1}, \mathrm{H}_{2}$ applicable to selected military devices are specified in the Table 1. Polish safety requirements for the protection of workers against exposure to electromagnetic fields are also described in the study conducted by Gryz and Karpowicz [6] and in Karpowicz et al.'s study [7].

\section{Occupational exposure to electromagnetic fields of Polish military personnel \\ Communication devices}

Modern military radio transceivers provide analogue or digital voice communication and data transmission and (excluding submarine communication) their operating range is between $1.5 \mathrm{MHz}$ and $2 \mathrm{GHz}$ and the transmitted power varies from $0.5 \mathrm{~W}$ to $1 \mathrm{~kW}$. According to the electromagnetic field exposure criteria, 3 groups of radio transceivers have been distinguished: portable and handheld radios, manpack radios and high frequency/very high frequency (HF/VHF) band devices installed in vehicles. Portable and handheld radios - small-sized, lightweight and short-range radios which provide communication in the very high frequency/ultrahigh frequency (VHF/UHF) band. The transmitted power varies from 0.5 to $5 \mathrm{~W}$. Notwithstanding low power, the electromagnetic field exposure is relatively high due to the construction and usage patterns of such devices - an antenna and a transceiver (combined into a single tool) are in close proximity to the operator's mouth during standard use.

The second group of radio transceivers are manpack radios. The operating frequency range of a manpack radio is $30-90 \mathrm{MHz}$. The transmitted power varies from 5 to $20 \mathrm{~W}$. Construction of a manpack radio allows it to be carried on shoulders (like a backpack) (Photo 1). It is possible to use the radio either on the shoulders or when it is placed on the ground. The maximum exposure occurs when the antenna is in close proximity to the human head (shoulder position).

The third group of radio transceivers includes HF/VHF band devices installed in vehicles that do not provide full electromagnetic shielding. Their operating frequency range is between 1.5 and $90 \mathrm{MHz}$ and the transmitted power varies from 50 to $1000 \mathrm{~W}$. A radio in a vehicle (the HF band, $1000 \mathrm{~W}$ ) with antennas on the roof is shown in the Photo 2. It is possible to use the radio either when the vehicle is moving or not. The electric field strength inside the vehicle depends on the vehicle dimensions, size of its windows, its material and distances from the antennas to personnel positions. Radios that support HF band are also equipped with additional masts in order to mount antennas. According to those construction standards the electromagnetic hazard is reduced because of the extended distance between the antennas and personnel.

This three-way division of military radio transceivers does not include devices that produce negligible electromagnetic field values in the workplaces of soldiers such as HF/VHF/UHF band devices installed in shelters and vehicles that provide full electromagnetic shielding. Obviously, adequate electromagnetic radiation protection is possible when all doors, hatches and window shades are closed.

\section{Surveillance radars, height finders, $3 \mathrm{D}$ radars}

Radars used in determining the occurrence, location and velocity of objects work in the frequency bands: VHF, UHF, L, S, C, X and Ku. The average transmitted power depends on the radar application and varies from $1 \mathrm{~W}$ (small marine radars) up to $10 \mathrm{~kW}$ (air route surveillance radars). The electromagnetic hazard produced by these devices is related to their transmitted power, antenna location and the shielding effectiveness of cabins where work positions are located.

Modern air route surveillance radar systems consist of an antenna unit, a transmitter and a receiver unit. Most 


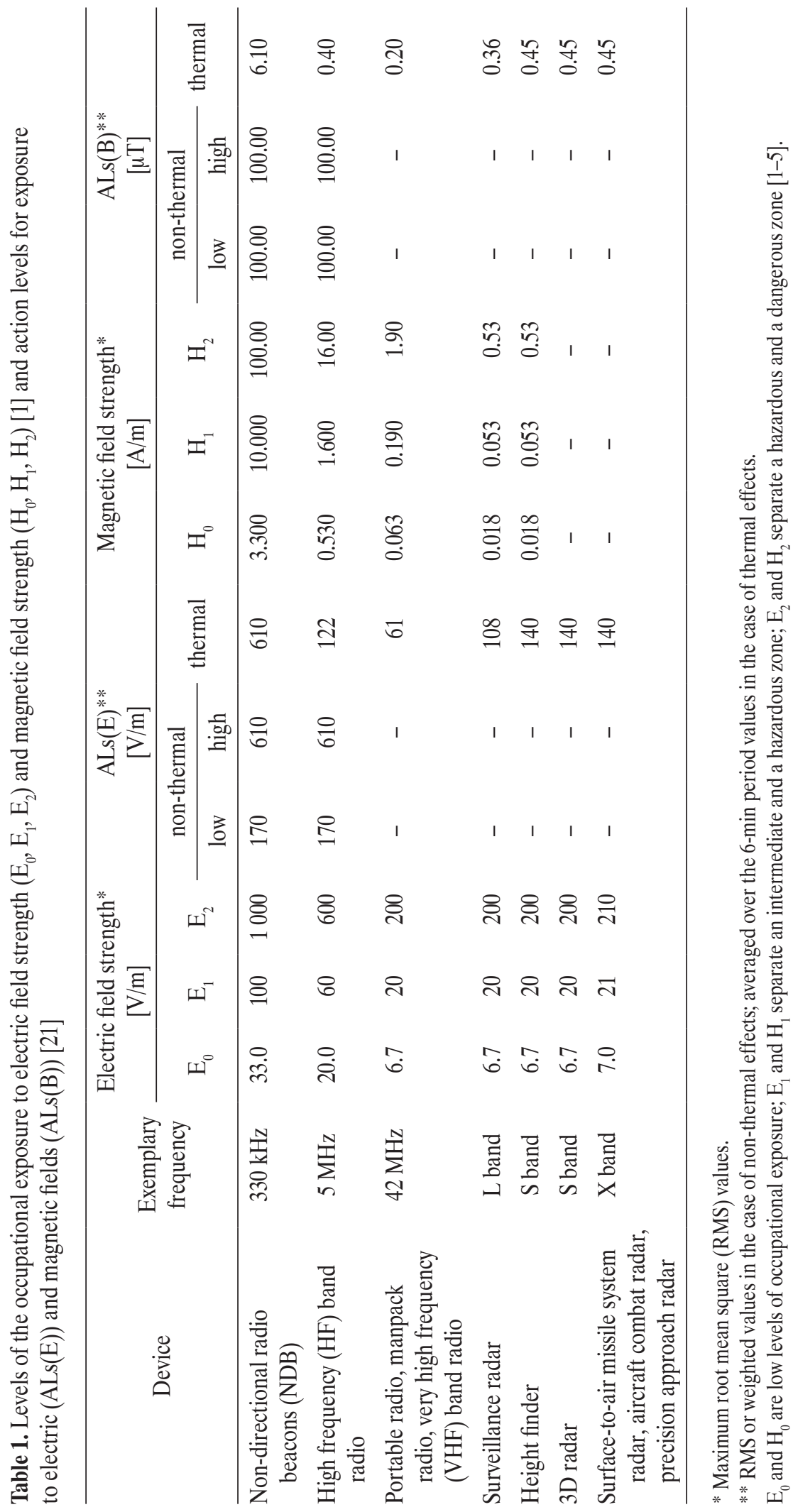




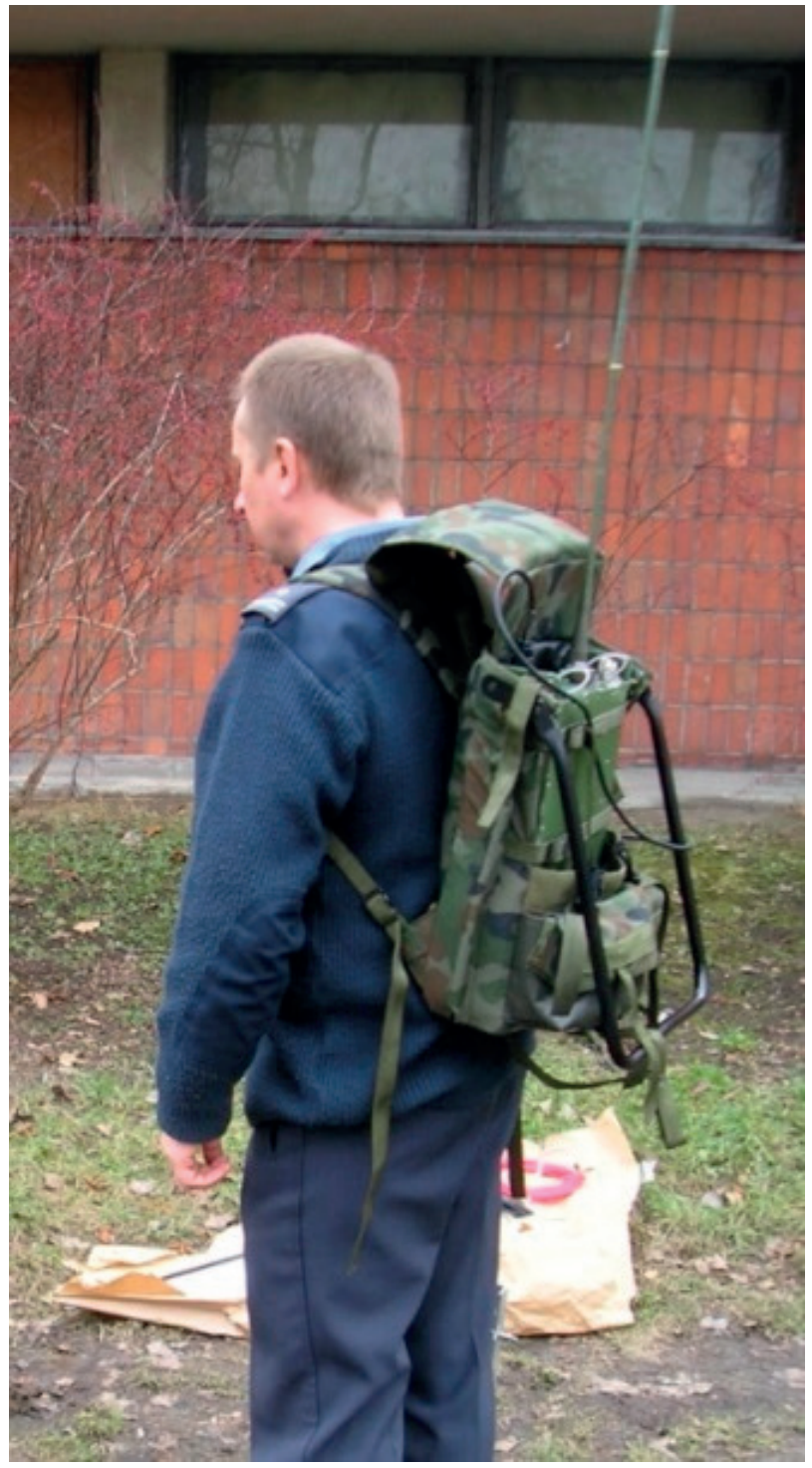

Photo 1. The manpack radio operator with the radio on the shoulders

of transmitters and receivers are placed in separate cabins. This solution protects personnel against excessive exposure to the electromagnetic field. Work positions are situated in the receiver unit where radar indicators are located. Soldiers stay temporarily in the transmitter unit and close to the antenna unit to check radar operating parameters.

The second group includes radars with a transmitter, receiver and antenna placed on one vehicle. The

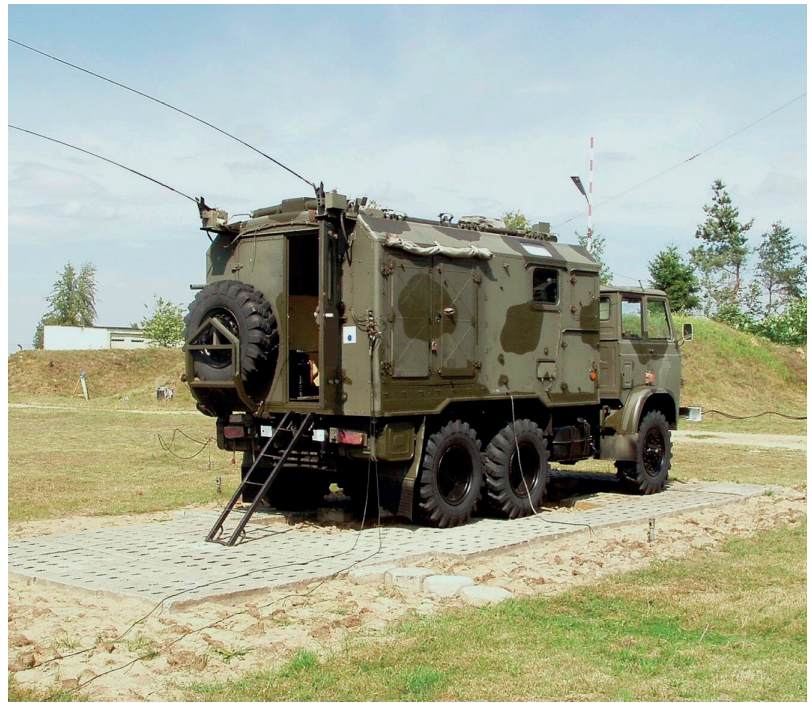

Photo 2. The radio in the vehicle

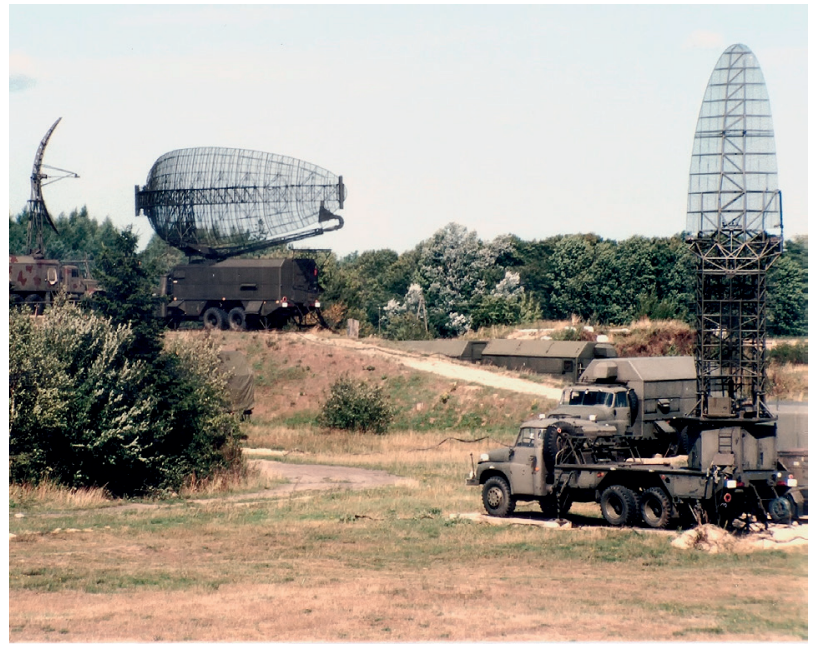

Photo 3. The radar post equipped with the range finder and 2 height finders

Photo 3 illustrates a radar post equipped with a range finder and 2 height finders on vehicles. Transmitter and receiver components are located near work positions, while the antenna is installed on a vehicle's roof. Military personnel are exposed to the electromagnetic field while being nearby a radar vehicle. Due to the insufficient shielding quality of cabinets which contain high power vacuum tubes and the fact that leakages may appear, electromagnetic radiation exposure may occur inside the vehicle. 
Marine radar systems mounted on ships have a comparable structure. Indicators are located on the bridge. The transmitter, receiver and antenna are combined in one unit and are located high above the deck. In some situations, the transmitter and receiver are located in the transmitter room, separately from the antenna. Personnel are not allowed to approach the antenna area while the radar is operating, and because of electromagnetic radiation (transmitter component leakages), visiting the transmitter room is restricted. Most of the personnel on ships are not exposed to the electromagnetic field from their own radar systems but rather face accidental exposure from the radar systems of other ships.

\section{Radars for surface-to-air missile systems}

Surface-to-air missile systems are equipped with dualfunction radars (searching and tracking). When in the search mode, the radar scans to find targets and determines their position, while in the tracking mode the radar tracks a target and follows its path. It is possible to use a single radar for both operational modes; however, using 2 different devices occurs more frequently. The antenna pattern during tracking mode is a narrow pencil beam and the radar also works with zero or negative elevation angles. Soldiers usually work inside transporter erector launchers or inside command cabins that provide electromagnetic shielding. The area around the radar antenna, where the launchers are located, is exposed to a high-intensity electromagnetic field emitted by the main beam of the tracking radar antenna.

\section{Airport radars and radio navigation systems}

Airport surveillance radars (ASR) and precision approach radars (PAR) provide target detection in the surrounding airspace. Usually, ASR/PAR are remotely controlled, thereby eliminating electromagnetic field exposure. In addition to modern ASR/PAR, the Polish Armed Forces still use the Soviet approach and landing systems shown in

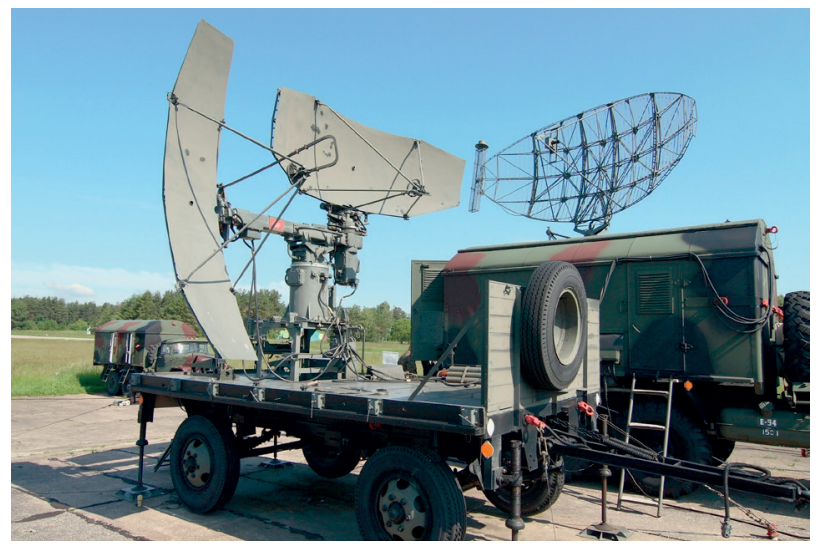

Photo 4. The approach and landing system

the Photo 4. Soldiers work inside cabins where radar components are located and because of leakages from cabinets containing high power vacuum tubes and other transmitter components, they are exposed to an electromagnetic field not only while tuning transmitters.

Ground stations for radio navigation systems are also controlled remotely. Soldiers are not exposed to the electromagnetic field emitted by this equipment. Non-directional radio beacons (NDB) are an exception. The radio transmitter is used as an aviation navigation aid. Non-directional radio beacons work in the low frequency/medium frequency (LF/MF) range. Non-directional radio beacons personnel are periodically exposed to an electromagnetic field while passing under the antenna and checking device parameters.

\section{Aircraft and helicopters}

Polish military aircraft and helicopters are equipped with many electronic systems (communication devices, radars, weather and electronic warfare systems) that produce an electromagnetic field. Ground handling personnel only remain for short periods within the electromagnetic field when an aircraft or helicopter is handled for the next flight (during which flight aircrews are not exposed to electromagnetic radiation). Devices mounted aboard determine the size of occupational protection zones, for example, a combat radar has the widest occupational protection zone. 


\section{MATERIAL AND METHODS}

\section{Subject of measurements}

Occupational exposure to electromagnetic fields was analyzed in the work environment of personnel of 204 devices divided into 5 groups (surface-to-air missile system radars, aircraft and helicopters, communication devices, surveillance radars, height finders and 3D radars, airport radars and radio navigation systems). When selecting devices their number in the armed forces was taken into account. The exact types and numbers of the devices as well as the amount of personnel required in each group are classified. Frequency band symbols for communication devices and radio navigation systems are defined in the International Telecommunication Union's (ITU) radio regulations [8]. Frequency bands for radars are in accordance with the standard governed by the Institute of Electrical and Electronics Engineers (IEEE) [9].

\section{Meters}

For electric field measurement purposes, MEH-25 broadband meters (Technical University of Wroclaw, Poland) with probes AE-1 and 3AE-2e, EMR-200 (Wandel \& Goltermann, Germany) with probes No. 9, 11 and EMF-5 (Military Institute of Hygiene and Epidemiology, Zenmarco, Poland) with probes SIN, SIT were used. For magnetic field measurement purposes, $\mathrm{MEH}-25$ meters with probes $\mathrm{AH}-1$ and AH-27 and EMR-200 with probe No. 10 were used.

$\mathrm{MEH}-25$ with AE-1, 3AE-2e probes works in the frequency range from $100 \mathrm{kHz}$ to $300 \mathrm{MHz}$ within the range of measured values from 0.5 to $1000 \mathrm{~V} / \mathrm{m}$. EMR-200 with probes No. 9 and 11 works in the frequency range from $10 \mathrm{MHz}$ to $60 \mathrm{GHz}$ and the range of measured values of the electric field strength is $0.5-1000 \mathrm{~V} / \mathrm{m}$. EMF-5 is designed to measure the electric field produced by radar systems, especially pulse trains with a very small duty cycle. EMF-5 works in the frequency range from $100 \mathrm{MHz}$ to $16 \mathrm{GHz}$. The range of measured root mean square (RMS) electric field strength values averaged over the pulse repetition period depends on the percent of signal duty cycle and starts from $0.5 \mathrm{~V} / \mathrm{m}$ for very short pulse and long repetition time trains and exceeds $3 \mathrm{kV} / \mathrm{m}$ for high percent of signal duty cycle.

For measurements of magnetic field purposes, MEH-25 meters with probes $\mathrm{AH}-1$ and $\mathrm{AH}-27$ and EMR-200 with probe No. 10 were used. The frequency range of MEH-25 is from $100 \mathrm{kHz}$ to $40 \mathrm{MHz}$, the range of measured values is between $0.6-250 \mathrm{~A} / \mathrm{m}$ (in the frequency range of $0.1-10 \mathrm{MHz}$ ) and $0.03-11 \mathrm{~A} / \mathrm{m}$ above $10 \mathrm{MHz}$. EMR-200 with probe No. 10 works in the frequency range from $27 \mathrm{MHz}$ to $1 \mathrm{GHz}$ and the range of measured values is $0.01-16 \mathrm{~A} / \mathrm{m}$.

The meters had been calibrated by the Electromagnetic Field Standards and Metrology Laboratory, Technical University of Wroclaw, Poland and the Laboratory of Electromagnetic Hazards, Department of Bioelectromagnetism, Central Institute for Labour Protection National Research Institute (Centralny Instytut Ochrony Pracy - Państwowy Instytut Badawczy - CIOP-PIB), Warszawa, Poland. EMR-200 with 9, 10, 11 probes had been calibrated with an extended dynamic range. The expanded measurement uncertainty (95\% confidence level) of the magnetic field strength is $30 \%$ while the electric field strength (excluding radar and surface-to-air missile systems) does not exceed 22\% whereas the electric field strength produced by radars and surface-to-air missile systems is $30 \%$.

\section{Exposure measurements conditions}

Measurements of the electric field strength of each device were made according to the Defense Standards $[4,5]$. Measurements of the magnetic field strength were made for each communication device and selected ground and onboard navigation devices. The measurements were carried out in places that are frequented by personnel, i.e., by indicators, device terminals, radio panels, above vehicle seats, at vehicle hatches, as well as at cabinets 
containing high power vacuum tubes and other transmitter components, at transmission lines, connectors, etc. The electromagnetic field was measured around vehicles and antenna units to the distance where the electric and magnetic fields fall below the low level of occupational exposure. The minimal distance from the meter probe to the source of the field or other metal objects was $15 \mathrm{~cm}$, but no closer than 3 outer probe dimensions. Measurements were carried out from the ground level to $2 \mathrm{~m}$ above it and the maximum RMS value of the electric field strength and the magnetic field strength found in this range of height was recorded (not averaged over any 6-min period).

\section{RESULTS}

\section{Communication devices}

Selected measurement results of electric and magnetic field strength of communication devices are shown in the Table 2. The data presented refers to portable radios, manpack radios and HF/VHF band devices mounted on vehicles.

Portable radios emit (close to human heads) the electric field strength from 20 to $80 \mathrm{~V} / \mathrm{m}$. The measured magnetic field strength was from 0.04 to $0.45 \mathrm{~A} / \mathrm{m}$. The maximum range of the hazardous zone nearby these devices was $50 \mathrm{~cm}$ and the maximum range of the intermediate zone was $1.2 \mathrm{~m}$ from a radio.
The manpack radio operator exposure depends on the placement of the equipment. When the radio is transported on the shoulders then the antenna is placed in close proximity (about $30 \mathrm{~cm}$ ) to the human head. It means that a soldier is exposed to the electric field strength from 60 to $120 \mathrm{~V} / \mathrm{m}$. The hazardous zone range is about $1 \mathrm{~m}$ and the intermediate zone reaches up to $3 \mathrm{~m}$ from the radio.

Inside vehicles with $\mathrm{HF} / \mathrm{VHF}$ band radios, the electric field strength is from 7 to $30 \mathrm{~V} / \mathrm{m}$. If the HF band antennas are placed on a truck, the hazardous zone outside the vehicle reaches about $2 \mathrm{~m}$ and the intermediate zone up to $5 \mathrm{~m}$. Whereas, when the HF band antenna is located on the mast, the hazardous zone reaches a distance of $1 \mathrm{~m}$ and the intermediate zone reaches up to $3 \mathrm{~m}$ from the antenna. Estimated ranges in the work environment of VHF band radios (mounted on off-road vehicles) are: $5 \mathrm{~m}$ for the hazardous zone and $15 \mathrm{~m}$ for the intermediate zone.

\section{Surveillance radars, height finders, 3D radars}

Selected measurement results of the electric field strength in the work environment of radiolocation devices are shown in the Table 3. The data presented refers to surveillance radars, height finders and 3D radars.

Operators of modern 3D surveillance radar systems work in the receiver unit, where only radar indicators are located. The electric field strength inside the transmitter

Table 2. Selected measurements of the electric and magnetic field strength in the work environment of communication devices

\begin{tabular}{|c|c|c|c|c|c|c|c|}
\hline \multirow{3}{*}{ Device } & \multirow{3}{*}{$\begin{array}{l}\text { Measurement } \\
\text { conditions }\end{array}$} & \multirow{3}{*}{$\begin{array}{c}\text { Frequency } \\
{[\mathrm{MHz}]}\end{array}$} & \multirow{3}{*}{$\begin{array}{c}\text { Transmitted } \\
\text { power } \\
\text { [W] }\end{array}$} & \multicolumn{4}{|c|}{ Personnel exposure } \\
\hline & & & & \multicolumn{2}{|c|}{$\begin{array}{l}\text { electric field strength }(\mathrm{E}) \\
{[\mathrm{V} / \mathrm{m}]}\end{array}$} & \multicolumn{2}{|c|}{$\begin{array}{l}\text { magnetic field strength }(\mathrm{H}) \\
{[\mathrm{A} / \mathrm{m}]}\end{array}$} \\
\hline & & & & $\min .-\max$ & $\mathrm{M} \pm \mathrm{SD}$ & $\min .-\max$ & $\mathrm{M} \pm \mathrm{SD}$ \\
\hline Portable radio & - & $42.0-50.0$ & $0.5-5.0$ & $20-80$ & $47 \pm 27$ & $0.04-0.45$ & $0.21 \pm 0.18$ \\
\hline Manpack radio & shoulder position & $30.0-90.0$ & $5.0-20.0$ & $60-120$ & $85 \pm 20$ & $0.11-0.28$ & $0.20 \pm 0.05$ \\
\hline $\begin{array}{l}\text { High frequency }(\mathrm{HF}) \\
\text { band radio }\end{array}$ & inside a vehicle & $1.5-30.0$ & 1000 & $7-30$ & $19 \pm 9$ & $0.00-0.06$ & $0.04 \pm 0.01$ \\
\hline
\end{tabular}

min. - minimal value; max - maximal value; $\mathrm{M}$ - mean; $\mathrm{SD}$ - standard deviation. 
Table 3. Selected measurements of the electric field strength in the work environment of radiolocation devices

\begin{tabular}{lllccc}
\hline Device & $\begin{array}{c}\text { Measurement } \\
\text { conditions }\end{array}$ & Frequency band & $\begin{array}{c}\text { Transmitted power } \\
{[\mathrm{kW} / \text { pulse }]}\end{array}$ & \multicolumn{2}{c}{$\begin{array}{c}\text { Personnel exposure to electric field } \\
\text { strength (E) } \\
{[\mathrm{V} / \mathrm{m}]}\end{array}$} \\
\hline 3D radar & at indicators & $\mathrm{L}, \mathrm{S}$ & & min.-max & M \pm SD \\
Range finder & at indicators & $\mathrm{L}$ & $80-800$ & 0 & - \\
Range finder & at indicators & VHF & $\approx 200$ & $0-20$ & $3.3 \pm 5.1$ \\
Height finder & at indicators & $\mathrm{S}$ & $\approx 200$ & $9-18$ & $12.8 \pm 3.5$ \\
\hline
\end{tabular}

VHF - very high frequency.

Other abbreviations as in Table 2.

unit is negligible but nearby the antenna unit the electric field strength RMS value averaged over the pulse repetition period and antenna rotation time is about $30 \mathrm{~V} / \mathrm{m}$. Occupational protection zones are only in the proximity of the antenna unit. The range of the hazardous zone is about $6 \mathrm{~m}$ and the intermediate zone reaches up to $30 \mathrm{~m}$ from the antenna.

Military personnel working inside a vehicle with transmitter and receiver components inside (the transmitter, receiver and antenna are installed in one vehicle) are potentially exposed to the electromagnetic field inside the cabin. This is due to the insufficient shielding quality of cabinets containing high power vacuum tubes and leakages from transmitter components. The electric field strength RMS value averaged over the pulse repetition period inside the cabin varies from 9 to $20 \mathrm{~V} / \mathrm{m}$. The electric field strength RMS value averaged over the pulse repetition period and antenna rotation time close to the range finder vehicle exceeds $20 \mathrm{~V} / \mathrm{m}$ whereas the electric field strength RMS value averaged over the pulse repetition period and antenna rocking time close to the height finder vehicle exceeds $200 \mathrm{~V} / \mathrm{m}$. The hazardous zone around the range finder vehicle reaches $6 \mathrm{~m}$ and the intermediate zone reaches up to $20 \mathrm{~m}$ whereas around the height finder vehicle the dangerous zone is about $3 \mathrm{~m}$ in distance, the hazardous zone reaches to $20 \mathrm{~m}$ and the intermediate zone up to $30 \mathrm{~m}$.

\section{Surface-to-air missile system radars}

Selected measurement results of the electric field strength in the work environment of surface-to-air missile systems are shown in the Table 4. The data presented refers

Table 4. Selected measurements of the electric field strength in the work environment of surface-to-air missile systems

\begin{tabular}{lllccc}
\hline \multicolumn{1}{c}{ Device } & \multicolumn{1}{c}{$\begin{array}{c}\text { Measurement } \\
\text { conditions }\end{array}$} & $\begin{array}{c}\text { Frequency } \\
\text { band }\end{array}$ & $\begin{array}{c}\text { Transmitted power } \\
{[\mathrm{kW} / \text { pulse }]}\end{array}$ & $\begin{array}{c}\text { Personnel exposure to electric field } \\
\text { strength (E) } \\
{[\mathrm{V} / \mathrm{m}]}\end{array}$ \\
\cline { 5 - 6 } & & $\mathrm{X}$ & $\approx 200$ & $0-15$ & $\mathrm{M} \pm \mathrm{SD}$ \\
\hline Radar command cabin & at indicators & $\mathrm{C}$ & $\approx 500$ & 0 & - \\
Radar transporter & at indicators & $\mathrm{C}$ & $\approx 500$ & 0 & - \\
Transporter launcher & above vehicle seats & $\mathrm{C}$ & & & \\
\hline
\end{tabular}

Abbreviations as in Table 2. 
to surface-to-air missile systems equipped with separate transporter launchers.

Operators of surface-to-air missile systems usually work inside command cabins or transporter erector launchers that provide electromagnetic shielding. Occasionally, due to any damage to cabin hatches, personnel are exposed to the electric field strength RMS value from 7 to $15 \mathrm{~V} / \mathrm{m}$. This situation happens very rarely only at selected azimuth and elevation angles of the tracking radar antenna. Outside the cabin at the distances up to $20 \mathrm{~m}$ from the antenna vehicle the electric field strength RMS value exceeds $200 \mathrm{~V} / \mathrm{m}$. These values of the electric field strength are measured on the direction of the main beam of the tracking radar antenna that works with zero or negative elevation angles. Outside the main lobe near the radar vehicle the electric field strength RMS value rarely exceeds $30 \mathrm{~V} / \mathrm{m}$. The electric field outside the main lobe of the tracking radar antenna is produced by its side and rear lobes and by the surveillance radar. At the point of the launcher placement, in the direction of the tracking radar antenna main beam, the electric field strength RMS value is from 80 to $110 \mathrm{~V} / \mathrm{m}$. Moreover, personnel are exposed to the electric field strength RMS value approx. $40 \mathrm{~V} / \mathrm{m}$ during transmitter tuning. The occupational protection zone ranges depend on the elevation angle of the tracking radar antenna. The intermediate zone reaches up to $400 \mathrm{~m}$ when the elevation angle is close to zero, while the hazardous zone radius is about $250 \mathrm{~m}$ and the dangerous zone extends up to $20 \mathrm{~m}$.

\section{Airport radars and radio navigation systems}

Airport surveillance radars/precision approach radars operators are not present in the electromagnetic field produced by antennas of these devices. In close proximity to the modern ASR antenna, the electric field strength is up to $20 \mathrm{~V} / \mathrm{m}$ and near the PAR antenna it exceeds $200 \mathrm{~V} / \mathrm{m}$. Values of the electromagnetic field as measured nearby the antennas of outdated ASR/PAR (Soviet production) are similar to modern systems. The electric field strength RMS value inside the cabin exceeds $10 \mathrm{~V} / \mathrm{m}$, but while transmitter tuning personnel are exposed to the electric field strength RMS value 30-40 V/m.

Ground station personnel of radio navigation systems are not exposed to the electromagnetic field produced by these systems. Only NDB operators are periodically exposed to the electric field strength from 100 to $150 \mathrm{~V} / \mathrm{m}$ while passing under the antenna in order to check device parameters.

\section{Aircraft and helicopters}

Aircrews while operating in flight are not exposed to the electromagnetic field produced by communication devices, radars and weather and electronic warfare systems. Ground handling personnel are only exposed for a short period when an aircraft or helicopter is handled for the next flight. Devices mounted aboard determine the size of occupational protection zones, for example, a combat radar has the most extended zones in its surrounding (the dangerous zone is up to $10 \mathrm{~m}$ in front of the aircraft, the hazardous zone about $20 \mathrm{~m}$ and the intermediate zone is up to $60 \mathrm{~m}$ ).

\section{DISCUSSION}

\section{Occupational exposure of personnel in the literature}

Mantiply et al. [10] present the measurement results of the electric field strength near handheld transmitters $5 \mathrm{~cm}$ away from any surface of the unit. Maximum fields near $2 \mathrm{~W}$ handheld radio operating at $164 \mathrm{MHz}$ were $470 \mathrm{~V} / \mathrm{m}$ and $0.73 \mathrm{~A} / \mathrm{m}$. In Gryz et al.'s study [11] 50 portable radiophones of conventional and trunked communication systems were investigated. The maximum electric field strength was measured $10 \mathrm{~cm}$ away from the antenna. For conventional systems with maximum output power of $4 \mathrm{~W}$ and for the trunked system with maximum output power of $4 \mathrm{~W}$ - the electric field strength values of $106 \mathrm{~V} / \mathrm{m}$ and $136 \mathrm{~V} / \mathrm{m}$ were recorded. In our study, the transmitted power varied from 0.5 to $5 \mathrm{~W}$ and 
the minimal distance from the meter probe to the radio was $15 \mathrm{~cm}$. The electric field strength near portable radios was from 20 to $80 \mathrm{~V} / \mathrm{m}$ and the magnetic field strength was from 0.04 to $0.45 \mathrm{~A} / \mathrm{m}$. Considering differences of measurement conditions (the transmitted power, frequency, distance to the radio), our results are slightly below the results presented in Mantiply et al.'s study [10] but correspond to Gryz et al.'s ones [11].

In our study, manpack radio operators were exposed to the electric field from 60 to $120 \mathrm{~V} / \mathrm{m}$. The range of the hazardous zone was about $1 \mathrm{~m}$ and the intermediate zone reached up to $3 \mathrm{~m}$. The transmitted power varied from 5 to $20 \mathrm{~W}$ and the frequency range was from 30 to $90 \mathrm{MHz}$. Our result confirmed previously studied assumptions $[12,13]$ where the electric field strength slightly exceeded $60 \mathrm{~V} / \mathrm{m}$.

Mantiply et al. [10] present a review of studies on the occupational exposure to electric fields associated with VHF mobile transmitters in various motor vehicles with different antenna configurations. In the case of tests made with $60 \mathrm{~W}, 164 \mathrm{MHz}$ frequency-modulated radios resulted in electric field strengths ranging from 3.4 to $30 \mathrm{~V} / \mathrm{m}$ whereas in the case of tests made with $100 \mathrm{~W}, 41 \mathrm{MHz}$ radios resulted in electric field strengths from 3.4 to $120 \mathrm{~V} / \mathrm{m}$ near an occupant. Tests using $100 \mathrm{~W}$ FM radios at 25, 35, 39, 51 and $145 \mathrm{MHz}$ in a mid-size vehicle resulted in fields from 50 to $150 \mathrm{~V} / \mathrm{m}$. Authors in this part of the study did not take into account magnetic field radiation. In our study inside vehicles equipped with HF/VHF band radios, the electric field ranged from 7 to $30 \mathrm{~V} / \mathrm{m}$ and the magnetic field strength - to $0.06 \mathrm{~A} / \mathrm{m}$. Results of our measurements differ from the results reviewed in Mantiply et al.'s study [10] but since the electric field strength inside the vehicle depends on the vehicle dimensions, the size of its windows, its material and distances from antennas to work positions, the differences observed are explainable. Measurement results performed under HF band antennas presented in Mantiply et al.'s study [10] confirmed our findings.
For 100 to $1400 \mathrm{~W}$ radios, various antenna configurations and frequency bands (80, 40, 20,15, and $10 \mathrm{~m}$ ) at a height of 1 to $2 \mathrm{~m}$, the electric field strength varied from 1 to $200 \mathrm{~V} / \mathrm{m}$. In our study, the hazardous zone (from 60 to $600 \mathrm{~V} / \mathrm{m}$ ) was measured at the distance of $1 \mathrm{~m}$ away from the antenna (placed on the mast) and the intermediate zone (from 20 to $60 \mathrm{~V} / \mathrm{m}$ ) was observed up to $3 \mathrm{~m}$.

Our measurement showed that inside the radar cabin the electric field strength RMS value averaged over the pulse repetition period that ranged from 9 to $20 \mathrm{~V} / \mathrm{m}$ and in the proximity of the antenna unit of the surveillance radar the electric field strength RMS value averaged over the pulse repetition period and antenna rotation time was about $30 \mathrm{~V} / \mathrm{m}$. These values are close to results presented in the literature. In Danulescu's study [14] the average power density at radar workplaces was measured. At frequencies around 2-6 GHz the average power densities were $0.04-0.5 \mathrm{~mW} / \mathrm{cm}^{2}(12-43 \mathrm{~V} / \mathrm{m}$ calculated from the plane wave condition), and at frequencies smaller than $2 \mathrm{GHz}$ : 0.3-1 mW/cm² (33-61 V/m). In Szmigielski's study [15] the whole population of military personnel in Poland during the years of 1971-1985 became the study subject. The evaluation of the exposure revealed that $80-85 \%$ of service (mostly pulse-modulated at $150-3500 \mathrm{MHz}$ ) $2 \mathrm{~W} / \mathrm{m}^{2}(27 \mathrm{~V} / \mathrm{m})$ was not exceeded and exposures exceeding $6 \mathrm{~W} / \mathrm{m}^{2}(48 \mathrm{~V} / \mathrm{m})$ were registered incidentally.

Our study showed that personnel on ships were not exposed to the electromagnetic field emitted by their own radar systems. Because of leakages from transmitter components, personnel may be exposed only in the transmitter room. Similar conclusions are presented in GarajVrhovac et al.'s study [16] where the electromagnetic field strength was measured at assigned marine radar frequencies $(3 \mathrm{GHz}, 5.5 \mathrm{GHz}$ and $9.4 \mathrm{GHz}$ ) working with peak power of $50-60 \mathrm{~kW}$. The power density averaged over the pulse repetition period and the radar antenna rotation period was no more than $0.0002 \mathrm{~W} / \mathrm{m}^{2}(0.3 \mathrm{~V} / \mathrm{m})$ at the radar operator workplace and $0.004 \mathrm{~W} / \mathrm{m}^{2}(1.2 \mathrm{~V} / \mathrm{m})$ in 
the day rest area and sleeping quarters. Unfortunately, an accidental exposure is possible from the radar systems of other ships. In Moen et al.'s study [17], an incident at sea is reported. A part of a crew on a Norwegian naval ship was exposed to radar waves from an American destroyer for approx. $7 \mathrm{~min}$. The American ship passed at the distance of about 70-100 m away from the Norwegian ship and the mean power density then would be approximately $5.5 \mathrm{~kW} / \mathrm{m}^{2}(1.4 \mathrm{kV} / \mathrm{m})$.

Hjollund and Bonte [18] indicated the exposure of Danish military personnel operating mobile ground-to-air missile units that used several microwave emitting radar systems. In this study the maximal mean exposure was estimated to be $0.01 \mathrm{~mW} / \mathrm{cm}^{2}(6 \mathrm{~V} / \mathrm{m})$. Short term exposures of approximately $1 \mathrm{~mW} / \mathrm{cm}^{2}(61 \mathrm{~V} / \mathrm{m})$ might occasionally occur. It confirms our results for close to surface-to-air missile launchers in the direction of the main beam of the tracking radar antenna (occasional and short-lasting exposure) where the electric field strength RMS value ranged from 80 to $110 \mathrm{~V} / \mathrm{m}$.

In Joseph et al.'s study [19], the electromagnetic field exposure of workers and the general public from non-directional beacons (NDB) for air traffic control is assessed and characterized. The average of total values for all locations equaled 379.2 V/m. In Cooper et al.'s study [20], the electric field was measured at 3 types of the air traffic control site, hosted radars and navigation and communication systems. Electric field strengths at locations typically occupied by engineers when attending a Doppler VHF omnidirectional range/distance measuring equipment (DVOR/DME) site were $1 \mathrm{~V} / \mathrm{m}$. The electric field strength measured at non-directional beacons were at or below $300 \mathrm{~V} / \mathrm{m}$. It confirms our results for close-toground stations of radio navigation systems. The Polish military personnel are not exposed to the electromagnetic field produced by these systems except for the NDB where personnel are periodically exposed to the electromagnetic field strength from 100 to $150 \mathrm{~V} / \mathrm{m}$.

\section{Exposure of military personnel}

\section{and European Union provisions}

Maximum values of the electric field strength (RMS values) measured at work positions of military personnel have been compared to action levels established in the Directive 2013/35/EU [21]. This comparison is justified because in most cases military personnel are continuously exposed to the electromagnetic field for longer than 6 min (e.g., tuning of the tracking radar transmitter lasts from $15 \mathrm{~min}$ to $2 \mathrm{~h}$ ).

Action levels for exposure to electric field established [21] at work positions of the Polish military personnel working next to aircrafts, helicopters, radio navigation systems, airport radars, surface-to-air missile system radars, surveillance radars, height finders, 3D radars and most communication devices are not exceeded.

The case of manpack and portable radios is a near-field exposure case. Compliance with exposure limit values established in the Directive 2013/35/EU [21] shall be determined dosimetrically (compare [22]). In the Polish Armed Forces, according to the Decision [3], in the frequency range $0.003-100 \mathrm{MHz}$ while the exposure is highly localized and the electric and magnetic field strength exceeds appropriate occupational exposure levels, restrictions for induced currents established in the Standardization Agreement No. 2345 [23] are applicable. This issue is the subject of our separate research [12,13,24]. Above $100 \mathrm{MHz}$, while the exposure is highly localized, only the occupational exposure levels $\left(\mathrm{E}_{0}, \mathrm{E}_{1}, \mathrm{E}_{2}, \mathrm{H}_{0}, \mathrm{H}_{1}, \mathrm{H}_{2}\right)$ are applicable.

\section{CONCLUSIONS}

According to the regulations [1-5], in 57\% of military devices Polish soldiers work in the occupational protection zones. In $35 \%$ of cases, soldiers work in intermediate and hazardous zones and in $22 \%$ - only in the intermediate zone. In $43 \%$ of devices, military personnel are not exposed occupationally to an electromagnetic field. The largest percentage of soldiers work in the occupational 
protection zones nearby aircraft and helicopters. This exposure occurs only in the case of ground handling personnel while testing avionics. The smallest percentage of soldiers (excluding manpack and portable radio operators) work in occupational protection zones nearby communication devices. These workplaces are often located in electromagnetically shielded cabins or are sufficiently far away from masts with antennas.

\section{REFERENCES}

1. [Regulation of the Minister of Labour and Social Policy of 6 June 2014 on the maximum admissible concentrations and intensities for agents harmful to health in the working environment. J Laws 2014, item 817]. Polish.

2. [Decision of Minister of National Defence 98/MON of 31 March 2006 on compliance with safety rules with regard to use devices that produce electromagnetic radiation in the national defence branch. Off J Ministry National Defence 2006, No. 6, item 65]. Polish.

3. [Decision of Minister of National Defence 50/MON of 6 February 2008 changing the decision on compliance with safety rules with regard to use devices that produce electromagnetic radiation in the national defence branch. Off $\mathrm{J}$ Ministry National Defence 2008, No. 3, item 17]. Polish.

4. Military Centre for Standardization, Quality and Codification. [Health and safety at work - Protection against electromagnetic radiation - Part 1: General requirements (Defence Standard No. NO-06-A215-1:2007)]. Warszawa: The Centre; 2007. Polish.

5. Military Centre for Standardization, Quality and Codification. [Health and safety at work - Protection against electromagnetic radiation - Part 2: Test methods (Defence Standard No. NO-06-A215-2:2007)]. Warszawa: The Centre; 2007. Polish.

6. Gryz K, Karpowicz J. [Measurements of electromagnetic fields and evaluation of occupational exposure: PN-T06580:2002 requirements and principles adopted in the European Union]. Med Pr. 2003;54(3):279-84. Polish.
7. Karpowicz J, Hietanen M, Gryz K. EU Directive, ICNIRP guidelines and Polish legislation on electromagnetic fields. Int J Occup Saf Ergon. 2006;12(2):125-36, https://doi.org/10. 1080/10803548.2006.11076675.

8. International Telecommunication Union (ITU). Radio regulations articles. Geneva: The Union; 2012.

9. Institute of Electrical and Electronics Engineers (IEEE). IEEE Standard letter designations for radar-frequency bands (IEEE Standard 521-2002). New York: The Institute; 2003.

10. Mantiply ED, Pohl KR, Poppell SW, Murphy JA. Summary of measured radiofrequency electric and magnetic fields $(10 \mathrm{kHz}$ to $30 \mathrm{GHz}$ ) in the general and work environment. Bioelectromagnetics. 1997;18(8):563-77, https:// doi.org/10.1002/(SICI)1521-186X(1997)18:8<563::AIDBEM5 > 3.0.CO;2-0.

11. Gryz K, Zradziński P, Karpowicz J, Leszko W. [Measurement and assessment of electromagnetic fields near radiophones in line with provisions of European Directive 2013/35/EU and Polish labour law]. Med Pr. 2013;64(5):671-80, https:// doi.org/10.13075/mp.5893.2013.0069. Polish.

12. Kieliszek J, Sobiech J. [Induced current measurements in the body of manpack radio operators]. Przegl Elektrotechn. 2009;12:73-5. Polish.

13. Kieliszek J, Sobiech J, Stankiewicz W, Rongies W. [Measurements of induced currents as the part of assessment of professional exposition on electromagnetic field]. Przegl Elektrotechn. 2010;12:65-7. Polish.

14. Danulescu R. Assessment of complex microwaves occupational exposure in radar maintenance activity [Internet]. Vienna: International Radiation Protection Association; 1996 [cited 2015 Dec 10]. Available from: http://www.irpa.net/ irpa9/cdrom/VOL.3/V3_246.PDF.

15. Szmigielski S. Cancer morbidity in subjects occupationally exposed to high frequency (radiofrequency and microwave) electromagnetic radiation. Sci Total Environ. 1996;180(1): 9-17, https://doi.org/10.1016/0048-9697(95)04915-0.

16. Garaj-Vrhovac V, Gajski G, Pažanin S, Sarolić A, Domijan AM, Flajs D, et al. Assessment of cytogenetic damage 
and oxidative stress in personnel occupationally exposed to the pulsed microwave radiation of marine radar equipment. Int J Hyg Environ Health. 2011;214(1):59-65, https://doi. org/10.1016/j.ijheh.2010.08.003.

17. Moen BE, Møllerløkken OJ, Bull N, Oftedal G, Mild KH. Accidental exposure to electromagnetic fields from the radar of a naval ship: A descriptive study. Int Marit Health. 2013;64(4):177-82, https://doi.org/10.5603/IMH.2013.0001.

18. Hjollund NH, Bonte JP. Semen analysis of personnel operating military radar equipment. Reprod Toxicol. 1997;11(6): 897, https://doi.org/10.1016/S0890-6238(97)00074-9.

19. Joseph W, Goeminne F, Vermeeren G, Verloock L, Martens L. In situ exposure to non-directional beacons for air traffic control. Bioelectromagnetics. 2012;33(3):274-7, https://doi.org/10.1002/bem.21706.

20. Cooper TG, Mann SM, Blackwell RP, Allen SG. Occupational exposure to electromagnetic fields at Radio Transmitter Sites (HPA-RPD-026 Report) [Internet]. Chilton, Oxfordshire: Health Protection Agency; 2007 [cited 2015 Dec 10]. Available from: http://www.hpa.org.uk/webc/hpawebfile/hpa web_c/1194947392257.
21. Directive 2013/35/EU of the European Parliament and of the Council of 26 June 2013 on the minimum health and safety requirements regarding the exposure of workers to the risks arising from physical agents (electromagnetic fields) (20th individual Directive within the meaning of Article 16(1) of Directive 89/391/EEC) and repealing Directive 2004/40/EC. Off J Eur Union. 2013;56: L 179/1-21.

22. Zradziński P, Leszko W, Karpowicz J, Gryz K. [Assessment of the portable radiophone users' exposure to electromagnetic fields, with use of numerical simulations and Directive 2013/35/EU requirements]. Med Pr. 2013;64(6):817-27, https://doi.org/10.13075/mp.5893.2013.0070. Polish.

23. NATO Standardization Agency (NSA). Evaluation and control of personnel exposure to radio frequency fields $3 \mathrm{kHz}$ to $300 \mathrm{GHz}$ (Standardization Agreement STANAG No. 2345, Edition 3). Brussels: The Agency; 2003.

24. Sobiech J, Kieliszek J, Stankiewicz W. [Model of work environment in numerical evaluation of exposure of manpack radio operators to electromagnetic fields]. Przegl Elektrotech. 2011;12b:152-4. Polish.

This work is available in Open Access model and licensed under a Creative Commons Attribution-NonCommercial 3.0 Poland License - http://creativecommons.org/ licenses/by-nc/3.0/pl/deed.en. 